\title{
ENZYMATIC AND CHEMICAL MODIFICATIONS OF LIPOPEPTIDE ANTIBIOTIC A21978C: THE SYNTHESIS AND EVALUATION OF DAPTOMYCIN (LY146032)
}

\author{
Manuel Debono, Bernard J. Abbott, R. Michael Molloy, David S. Fukuda, \\ Ann H. Hunt, Veronica M. Daupert, Frederick T. Counter, \\ John L. Ott, Claude B. Carrell, Leonard C. Howard, \\ LAVERne D. Boeck and RoBert L. HaMill \\ Lilly Research Laboratories, Lilly Corporate Center, \\ Indianapolis, Indiana 46285 , U.S.A.
}

(Received for publication March 7, 1988)

\begin{abstract}
The novel lipopeptide antibiotic A21978C complex is active against Gram-positive organisms. This complex consists of a common peptide nucleus with various lipid acyl groups at the $\mathrm{N}$-terminus characteristic of each individual factor. The fatty acid acyl group is removed by incubation of the A21978C complex with Actinoplanes utahensis to give the peptide nucleus. This peptide nucleus has the same amino acid sequence as A21978C. New analogs of A21978C were synthesized by acylation of the $N$-terminus of a tert-butoxycarbonyl (tert-BOC)-protected nucleus and subsequent deprotection. ${ }^{1} \mathrm{H}$ NMR showed that the newly introduced acyl group was at the desired $N$-terminus. Three major groups of analogs were synthesized bearing fatty acid acyl, amino-aroyl and extended peptide side chains. Each analog was evaluated for antimicrobial activity and acute toxicity. Of these analogs, the $n$-decanoyl analog of A21978C (LY146032) gave the best survival in the mouse acute toxicity test at a high dose of $1,000 \mathrm{mg} / \mathrm{kg}$, iv and was chosen for further study. This analog has been named daptomycin.
\end{abstract}

Several classes of antibiotics such as the lipopeptides and the glycopeptides have resisted extensive systematic modification primarily due to their complex chemical structures. However, availability of more precise analytical methods and isolation techniques now make their modification more feasible.

A21978C complex is a family of lipopeptide antibiotics, produced by Streptomyces roseosporus. ${ }^{12}$ The structures of the major components are shown in Fig. 1. Each member of this family has the same thirteen amino acid peptide core or "nucleus" but differs in the structure of the fatty acid which acylates the $N$-terminus. A21978C factors $C_{1}, C_{2}$ and $C_{3}$ have acyl groups which are composed of branched fatty acids having 11,12 and 13 carbon atoms, respectively. The A21978C family illustrates some of the common characteristics of the lipopeptide class. The major feature of this class includes a short peptide of 5 to 15 amino acids which may be arranged into a linear form or in a cyclic array, or a combination of both, as they are in A21978C. These amino acids may have unusual structures, such as the D-amino acids L-kynurenine (kyn) and 3-methylglutamic acid residues found in A21978C. The $N$-terminus of this peptide is invariably $N$-acylated by a lipid group, usually a fatty acid having 10 to 18 carbon atoms which may be linear or branched. As a class, lipopeptide antibiotics exhibit a wide variety of antimicrobial actions, including activity against Gram-positive and Gram-negative bacteria or fungi. Distinct structural features control the nature of the antimicrobial spectrum. ${ }^{2)}$ Each of the A21978C factors has excellent activity against Gram-positive bacterial infections (Table 1). ${ }^{3 \sim 5)}$ 
Fig. 1. Structure of A21978C.

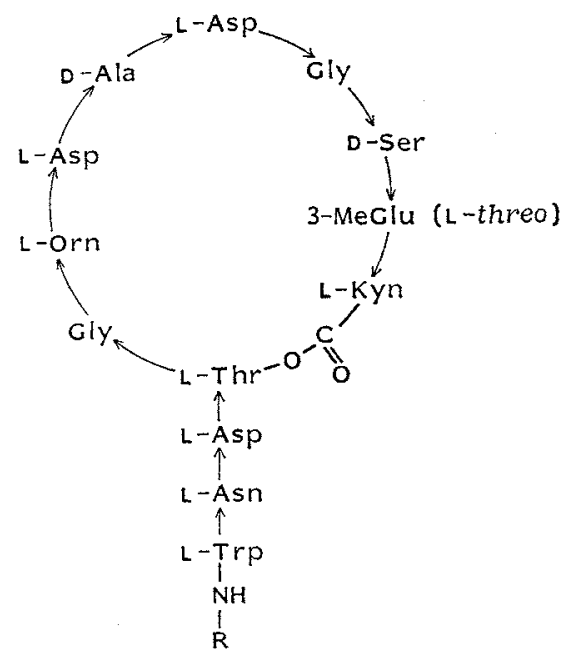<smiles>[R]C#CCC(C)CCCCCCCCC(=O)C([Y])[Y]</smiles>

Table 1. In vivo activity and acute toxicity of A21978C factors.

\begin{tabular}{|c|c|c|c|}
\hline \multirow[b]{2}{*}{ Factor } & \multicolumn{2}{|c|}{ Mouse $\mathrm{ED}_{50}(\mathrm{mg} / \mathrm{kg} \times 2, \mathrm{sc})$} & \multirow{2}{*}{$\begin{array}{c}\text { Mouse } \\
\text { toxicity, } \\
\text { LD }_{50} \\
\text { (mg/kg, } \\
\text { iv) }\end{array}$} \\
\hline & $\begin{array}{c}\text { Staphylococcus } \\
\text { aureus }\end{array}$ & $\begin{array}{l}\text { Streptococcus } \\
\text { pyogenes }\end{array}$ & \\
\hline $\mathrm{A}^{2} 1978 \mathrm{C}_{1}$ & 0.22 & 0.064 & $>600$ \\
\hline $\mathrm{A} 21978 \mathrm{C}_{2}$ & 0.16 & 0.030 & 175 \\
\hline $\mathrm{A} 21978 \mathrm{C}_{3}$ & 0.08 & 0.032 & 75 \\
\hline
\end{tabular}

We noted, however, that the acute toxicity increased with small increases in the chain length of the lipid side chain. This illustrates the functional importance of the side chain to the antimicrobial and toxicological properties of the lipopeptides. The structural diversity of the lipopeptides presents modification opportunities

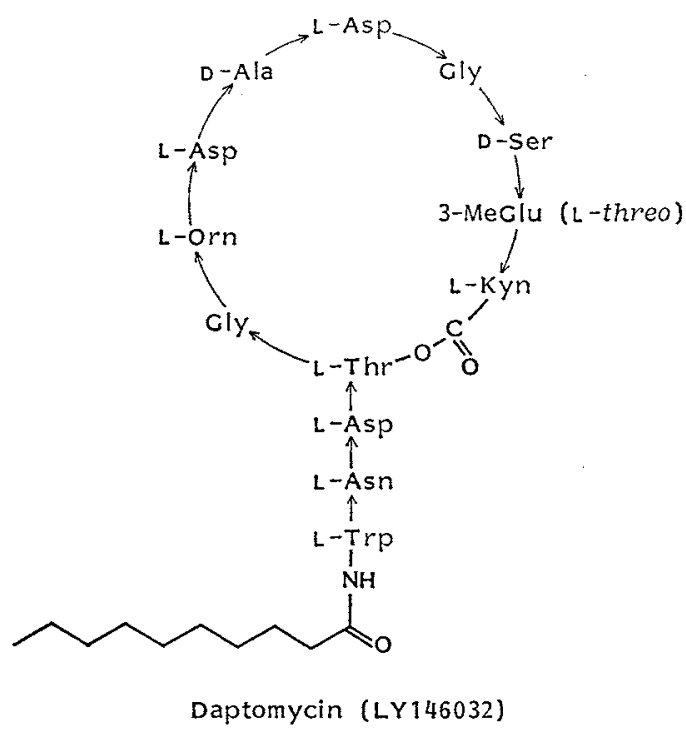
if it is possible to remove the acyl side chain and reintroduce a new acyl side chain. This paper will report the chemical modification of the lipopeptide A21978C to produce the superior analog daptomycin (LY146032). ${ }^{3,6}$ )

\section{Deacylation of A21978C}

Since the closely related $\mathrm{A} 21978 \mathrm{C}$ factors are co-produced in the fermentation, very laborious separation techniques were necessary to separate the desired $A 21978 C_{1}$ from the more toxic $C_{2}$ and $\mathrm{C}_{3}$ factors (Table 1). The solution to this problem was achieved by removing the native acyl side chains to give the common peptide "nucleus" and subsequently reacylating with a desired acyl group to give an analog, and assaying the analogs to find improved therapeutic properties.

Interest in this approach came about as a result of structural studies on A21978C." ${ }^{1}$ Sequencing this peptide by the EDMAN method required removal of the acyl group." This was accomplished 


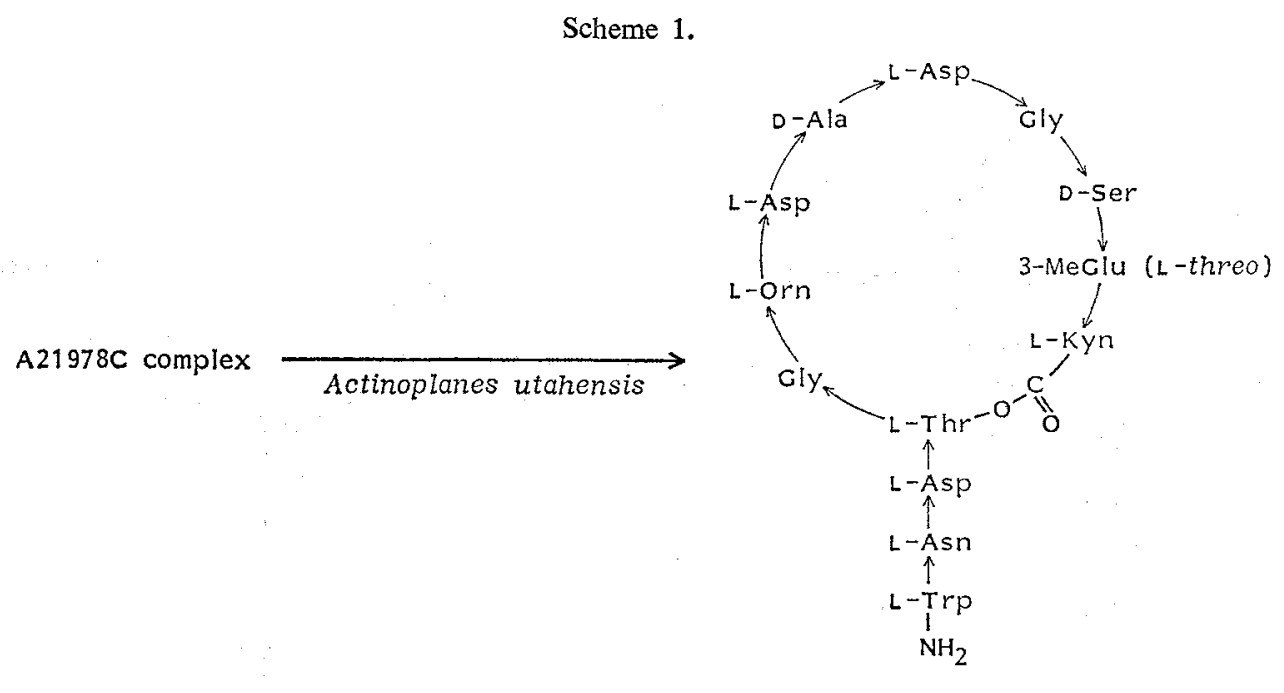

A21978C nucleus

enzymatically with polymyxin acylase using an acetone powder of Pseudomonas species M-6-3. ${ }^{8)}$ A similar preparation was used extensively by SHoJ in series of lipopeptide structure studies. ${ }^{92}$ This method generally resulted in production of deacylated peptide in $20 \sim 30 \%$ yield. When polymyxin acylase was used to deacylate $\mathrm{A} 21978 \mathrm{C}$, extensive cleavage of the lactone ring was observed. Therefore, a more selective means to carry out this transformation was required, and a series of organisms was screened for their ability to deacylate A21978C.

A group of Actinoplanes cultures known to have penicillin deacylase activity was included in the cultures which were screened. ${ }^{10)}$ This group was shown to deactivate A21978C by deacylation. One culture in particular, Actinoplanes utahensis NRRL 12052, was very effective and was used throughout these studies.

When A21978C complex was added to growing cultures of $A$. utahensis, a gradual disappearance of the added antimicrobial activity was observed. The fermentation was harvested, and the products were purified on Diaion HP-20 resin to give the deacyl-A21978C peptide in $50 \sim 60 \%$ yield with an efficiency of $70 \sim 80 \%$.

Physical and chemical data showed that the product lacked the fatty acid side chain while retaining the peptide structure, which showed no change in the amino acid composition or lactone bond. The potentiometric titration of the resulting peptide showed the generation of a new amino group at the $N$-terminal amino acid. This peptide lacked antimicrobial activity. It was observed that antimicrobial activity could be reconstituted by contact with acylating agents such as acid chlorides. This property was used to monitor the deacylation by paper chromatography and TLC. The deacylation reaction mixtures were applied to the chromatographic support and developed with the appropriate solvent. Bioautography at this stage showed that the only bioactive spots belonged to residual starting material (A21978C). The chromatogram was then sprayed with, or dipped into, a solution of n-octanoyl chloride, followed by a solvent wash to remove excess acylating agent and a new bioactive spot was observed at the location of the nucleus. These observations indicated that the A21978C complex had been converted to an inactive peptide and that this peptide could be reacylated to bioactive compound. 
Scheme 2.

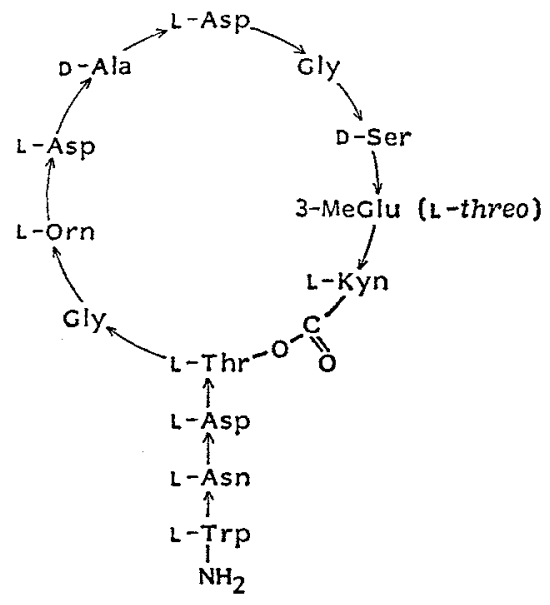

A21978C nucleus

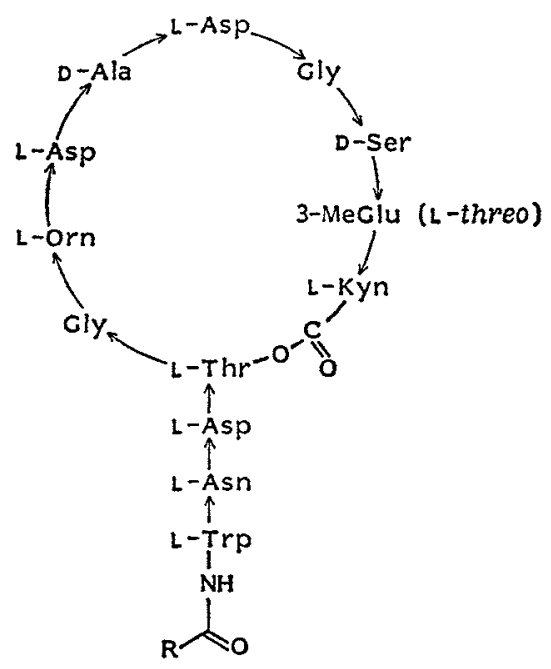

A21978C analog

Isolation of the A21978C nucleus represented a unique opportunity for synthesis of previously unavailable analogs of lipopeptides by selective reacylation. A21978C nucleus has several polar groups, of which four are potentially acylatable: The kynurenine aryl amino group, the serine hydroxyl, the amino side chain at ornithine (Orn), as well as the newly generated terminal amino group at tryptophan.

\section{Acylation of the A21978C Nucleus}

Acylation of the A21978C nucleus was approached by a number of methods. Direct acylation with acyl halides gave a mixture of products. Chromatographic separation showed that these products consisted of a mixture of monoacylated products and minor amounts of diacylated products. The array of products depended somewhat on the reaction conditions as well as the choice of acylating agent. Acyl halides gave a mixture of monoacyl products from which the desired product acylated at the $N$-terminal Trp residue could be obtained by chromatographic purification. However, appreciable amounts of the monoacyl-adduct acylated at the ornithine side chain were produced along with minor amounts of diacyl products. Use of active esters as the acylating agent presented a better alternative. Active esters of 2,3,5-trichlorophenol (TCP) gave a mixture of mono-acyl products with the desired monoacyl- $N$-Trp product. Similar results were obtained using active esters of $N$-hydroxysuccinimide. A greater measure of selectivity was obtained using acid chlorides and controlling the $\mathrm{pH}$ between 5.0 and 6.5. These conditions appeared to favor acylation at the $N$-terminus Trp. Use of active esters of $N$-hydroxybenztriazole (HBT) similarly gave acylation predominantly at the Trp residue with longer reaction times giving varying amounts of overacylation products. Active esters gave reaction mixtures that favored monoacylation and higher reaction yields $(50 \sim 60 \%)$. However, even under the best of conditions sufficient amounts of the undesired acylation products made the isolation and purification of the desired $N$-Trp monoacyl product difficult. The selectivity problem was solved by protecting the ornithine side chain in A21978C prior to deacylation.

Acylation at the ornithine side chain was avoided by the use of protecting groups as shown in 
Scheme 3. Preparation of A21978C analogs.

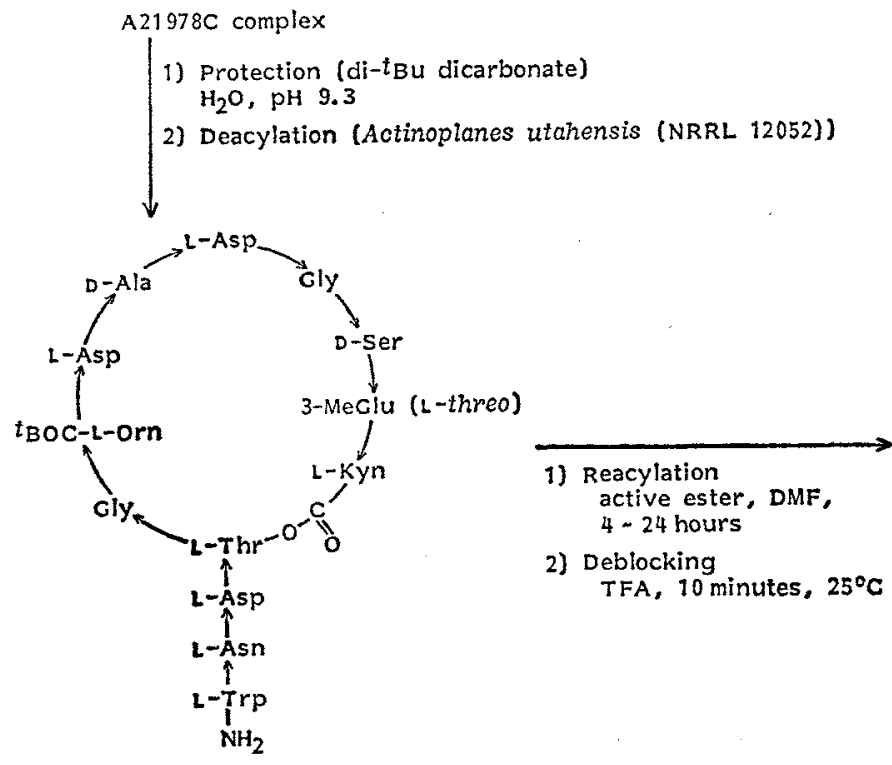

N-Orn-tert-BOC-A21978C nucleus

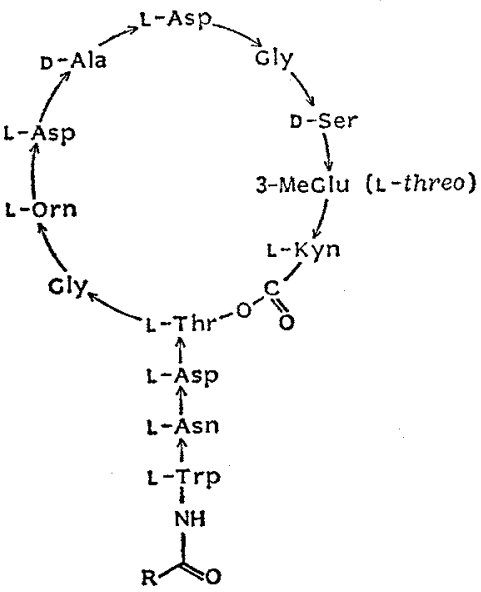

A21978C analog

Scheme 3. The A21978C complex was treated with di-tert-butyldicarbonate in aqueous solution at $\mathrm{pH}$ 9.3. This reaction gave an excellent yield of mono-tert-butoxycarbonyl (tert-BOC)-protected A21978C complex whose physical and chemical properties were consistent for a tert-BOC group at the ornithine amino group. This amino group was, therefore, eliminated as an acylation site and products acylated at the $N$-Trp-terminus would be strongly favored.

This protected antibiotic was added to the $A$. utahensis culture which enzymatically removed the native fatty acid acyl group to give $\mathrm{A} 21978 \mathrm{C}$ nucleus bearing a protected ornithine amino group. The tert-BOC protecting group survived the conditions employed in the fermentation and in the isolation. This protected peptide was acylated with TCP esters giving primarily monoacylation products at the desired $N$-terminal position (50 60\% yield) with only $5 \%$ diacylation occurring. Deblocking was effectively carried out using trifluoroacetic acid at room temperature for 10 minutes. This was done with minimal degradation and excellent product purity to yield new analogs of A21978C.

\section{Structural Examination of A21978C Analogs}

The number of acyl groups added to A21978C nucleus was determined by integration of the methyl resonances in the NMR spectra of the derivatives. Both mono-acyl and diacyl analogs were detected.

The sites of acylation for the A21978C derivatives were identified by comparing the $360 \mathrm{MHz}$ ${ }^{1} \mathrm{H}$ NMR spectra of the analogs with the spectrum of the underivatized nucleus. The addition of an acyl group is expected to alter the chemical shifts of protons adjacent to the acylation site; these potential reporter resonances include signals from the $\sigma$ methylene of ornithine, the $\beta$ methylene of serine, the $\alpha$ proton of tryptophan, and (less likely) the ring protons of the kynurenine residue. Failure of any of these resonances to shift was taken as evidence that acylation did not occur at that site. These 
Table 2. ${ }^{1} \mathrm{H}$ NMR data for selected semisynthetic A21978C analogs ${ }^{2}$.

\begin{tabular}{llcccl}
\hline \multirow{2}{*}{ Compound } & \multirow{2}{*}{ Acyl group } & \multicolumn{3}{c}{ Chemical shift (ppm) } & Acylation \\
\cline { 3 - 5 } & & Orn $\delta-\mathrm{CH}_{2}$ & Ser $\beta$ - $\mathrm{CH}_{2}$ & Trp $\alpha$-CH & \\
\hline A21978C nucleus & None & 2.78 & 3.68 & 3.87 & None \\
tert-BOC-A21978C & tert-BOC at Orn & 2.97 & 3.71 & & Orn \\
nucleus & & & & & \\
$\mathbf{4}$ & $n$-Decanoyl & 2.79 & 3.68 & 4.47 & Trp \\
$\mathbf{5}$ & $n$-Undecanoyl & 2.79 & 3.67 & 4.47 & Trp \\
$\mathbf{1 9}$ & $p$-Dodecanoylamidobenzoyl & 3.29 & 3.71 & & Orn \\
$\mathbf{1 4}$ & $n$-Undecanoyl-L-phenylalanyl & 3.03 & & & Orn \\
& Diundecanoyl & 3.02 & 3.71 & 4.46 & Orn, Trp \\
& Didecanoyl & 2.78 & 3.69 & 4.47 & Trp, Kyn \\
\hline
\end{tabular}

a Spectra obtained in DMSO solution, $23^{\circ} \mathrm{C}$.

results are shown in Table 2.

The ${ }^{1} \mathrm{H}$ NMR and mass spectral data for the $n$-decanoyl and $n$-undecanoyl A21978C analogs (compounds 4 and 5) showed that acylation in these derivatives occurred at the Trp residue at the peptide $N$-terminal. Other monoacylation products, formed in minor amounts which were dependent on reaction conditions, were acylated on the Orn $\sigma$-amino group. Diacylated A21978C derivatives, such as the di-undecanoyl analog, had acyl groups at both the Trp and Orn residues. Although the kynurenine aromatic amino group is potentially acylable, conditions used in this study did not result in extensive acylation at this site. A minor diacyl product, containing two $n$-decanoyl groups, was acylated at Trp and Kyn; the UV spectrum of this compound showed a shift in the kynurenine absorbance maximum from $360 \mathrm{~nm}$ to $320 \mathrm{~nm}$, and the kynurenine aromatic proton resonances were shifted downfield in the NMR spectrum of the material.

\section{Synthesis and Evaluation of A21978C Analogs}

These methods made it possible to synthesize analogs of the native A21978C antibiotic bearing a large variety of modifications in the acyl group. These analogs are summarized in Fig. 2. Table 3 includes some physical criteria for purity. The finding that subtle structural changes in the acyl group profoundly influenced the toxicity of the various A21978C factors predicted that modification of the side chain would be a fruitful method to design new analogs. However, there was no systematic way to choose among the possible structural variations.

In the discussion that follows, it will become apparent that there were some minimal structural features that were necessary for good antimicrobial activity. The chain length of an acyl group of at least four to eight carbon atoms was required to demonstrate detectable activity. Side chains that had complex structures appeared to require a long alkyl or acyl group somewhere in the overall structure for optimal activity. It also was possible to elongate the peptide by an amino acid and retain the same activity as long as an acyl side chain was present at the new $N$-terminus.

Three groups of analogs were synthesized by this method and included those bearing fatty acid acyl-, amino-aroyl-, and extended peptide side chains. Antimicrobial in vitro and in vivo activity and acute toxicity data for these analogs are shown in Table 4.

The data shown for compounds $1 \sim 10$, which are analogs bearing fatty acid acyl side chains, in- 
Fig. 2. Structure of A21978C analogs.

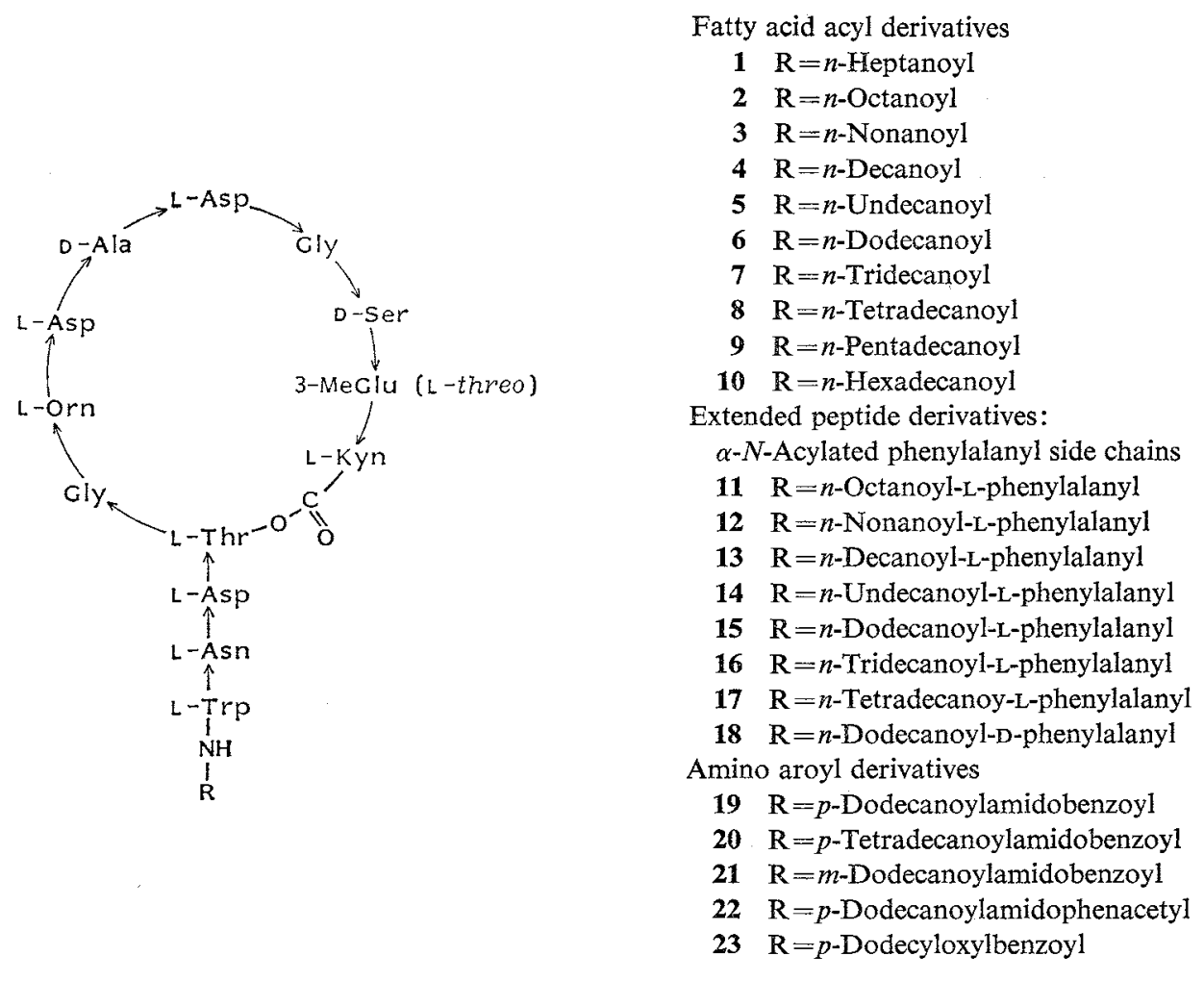

Table 3. Physical characteristics of A21978C derivatives.

\begin{tabular}{|c|c|c|c|c|c|c|c|c|c|}
\hline \multirow{2}{*}{$\begin{array}{l}\text { Com- } \\
\text { pound } \\
\text { No. }\end{array}$} & \multicolumn{2}{|c|}{ Extinction coefficients at } & \multirow{2}{*}{$\mathrm{Rf}$} & \multirow{2}{*}{ System } & \multirow{2}{*}{$\begin{array}{l}\text { Com- } \\
\text { pound } \\
\text { No. }\end{array}$} & \multicolumn{2}{|c|}{ Extinction coefficients at } & \multirow{2}{*}{ Rí } & \multirow{2}{*}{ System } \\
\hline & $\lambda_{\max }^{\mathrm{EtoH}} 220 \mathrm{~nm}$ & $\lambda_{\max }^{\mathrm{EtOH}} 260 \mathrm{~nm}$ & & & & $\lambda_{\max }^{\mathrm{EtOH}} 220 \mathrm{~nm}$ & $\lambda_{\max }^{E+O H} 260 \mathrm{~nm}$ & & \\
\hline $\mathbf{1}$ & 48,100 & 11,400 & 0.85 & a & 13 & 49,181 & 8,465 & 0.52 & $\mathrm{~b}$ \\
\hline 2 & 46,000 & 10,500 & 0.80 & a & 14 & 41,000 & 10,200 & 0.53 & b \\
\hline 3 & 46,000 & 11,000 & 0.75 & a & 15 & 52,997 & 9,435 & 0.54 & $\mathrm{~b}$ \\
\hline 4 & 46,500 & 10,000 & 0.70 & $\mathrm{a}$ & 16 & 47,025 & 8,823 & 0.56 & $b$ \\
\hline 5 & 46,200 & 10,400 & 0.65 & $\mathrm{a}$ & 17 & 48,410 & 9,007 & 0.65 & $b$ \\
\hline 6 & 44,000 & 9,500 & 0.59 & a & 18 & 44,600 & 8,970 & 0.54 & $b$ \\
\hline 7 & 48,500 & 9,800 & 0.53 & a & 19 & 57,000 & 28,531 & 0.34 & $b$ \\
\hline 8 & 48,447 & 9,170 & 0.42 & $\mathrm{a}$ & 20 & - & - & 0.83 & $b$ \\
\hline 9 & 50,172 & 9,751 & 0.34 & a & 21 & 58,270 & 19,027 & 0.57 & $\mathrm{~b}$ \\
\hline 10 & 54,000 & 12,000 & 0.25 & a & 22 & 48,992 & 21,505 & 0.74 & $b$ \\
\hline 11 & 44,504 & 8,899 & 0.48 & $\mathrm{~b}$ & 23 & 48,440 & 23,514 & 0.78 & $b$ \\
\hline 12 & 47,940 & 9,403 & 0.50 & b & & & & & \\
\hline
\end{tabular}

System a: Rf by reversed phase silica gel TLC (Whatman $\mathrm{KC}_{18}$ with fluorescent indicator) using a $\mathrm{H}_{2} \mathrm{O}-\mathrm{MeOH}-\mathrm{CH}_{3} \mathrm{CN}(45: 15: 40)$ with $0.2 \%$ pyridine and $0.2 \%$ AcOH solvent system.

System b: Rf by silica gel TLC (Merck) using a $\mathrm{H}_{2} \mathrm{O}-\mathrm{CH}_{3} \mathrm{CN}-\mathrm{Me}_{2} \mathrm{CO}(1: 2: 2)$ solvent system. -: Data not available.

dicate that the in vitro activity increased with acyl group up to chain length $\mathrm{C}-12$ to $\mathrm{C}-13$. The in vivo activity against Staphylococcus aureus and Streptococcus pyogenes followed a similar relationship. However, the $L D_{50}$ values showed that beyond the $C-11$ analog there is a definite trend toward increased toxicity. Presence of unsaturation in the side chain did not dramatically change these trends (data 
Table 4. Antimicrobial properties of A21978C derivatives.

\begin{tabular}{|c|c|c|c|c|c|c|}
\hline \multirow{2}{*}{$\begin{array}{l}\text { Compound } \\
\text { No. }\end{array}$} & \multicolumn{3}{|c|}{$\operatorname{MIC}(\mu \mathrm{g} / \mathrm{ml})$} & \multicolumn{2}{|c|}{$\begin{array}{c}\mathrm{ED}_{50}(\mathrm{mg} / \mathrm{kg} \times 2 \\
\text { mouse, } \mathrm{sc})\end{array}$} & \multirow{2}{*}{$\begin{array}{c}\mathrm{LD}_{50} \\
\text { (mg/kg, } \\
\text { iv) }\end{array}$} \\
\hline & $\begin{array}{c}\text { Staphylococcus } \\
\text { aureus }\end{array}$ & $\begin{array}{l}\text { Staphylococcus } \\
\text { epidermidis }\end{array}$ & $\begin{array}{l}\text { Streptococcus } \\
\quad \text { faecalis }\end{array}$ & S. aureus & $\begin{array}{c}\text { Streptococcus } \\
\text { pyogenes }\end{array}$ & \\
\hline $\mathrm{A} 21978 \mathrm{C}_{1}$ & 1 & 1 & 8 & 0.22 & 0.064 & $>600$ \\
\hline 1 & 8 & 8 & 128 & 2.65 & 1.49 & $>600$ \\
\hline 2 & 4 & 4 & 64 & 1.4 & 0.65 & $>600$ \\
\hline 3 & 8 & 8 & 128 & 0.5 & 0.14 & $>600$ \\
\hline 4 & 0.5 & 0.5 & 16 & 0.11 & 0.03 & 600 \\
\hline 5 & 0.25 & 0.5 & 2.0 & 0.27 & $>0.06$ & 450 \\
\hline 6 & 0.5 & 0.5 & 4.0 & 0.44 & 0.05 & 144 \\
\hline 7 & 0.125 & 0.5 & 0.03 & 0.54 & 0.046 & 112.5 \\
\hline 8 & 0.5 & 2 & 0.5 & 3.08 & 0.2 & 62.5 \\
\hline 9 & 1 & 4 & 2 & 8.3 & 0.18 & 56.3 \\
\hline 10 & 1 & 2 & 2 & 3.4 & 0.18 & 50 \\
\hline 11 & 4 & 8 & 128 & 2.58 & 1.48 & 450 \\
\hline 12 & 2 & 2 & 32 & 1.38 & 0.59 & $>600$ \\
\hline 13 & 0.5 & 0.5 & 8 & 0.99 & 0.15 & 600 \\
\hline 14 & 0.5 & 2 & 4 & 1.25 & 0.32 & 400 \\
\hline 15 & 0.5 & 1 & 1 & 2.35 & 0.32 & 250 \\
\hline 16 & 0.5 & 2 & 0.25 & 0.76 & 0.14 & 225 \\
\hline 17 & 0.5 & 4 & 1 & 4.8 & $>0.36$ & 225 \\
\hline 18 & 0.5 & 4 & 1 & 2.05 & 0.21 & 250 \\
\hline 19 & 2 & 16 & 32 & - & 18.8 & $<300$ \\
\hline 20 & 1 & 4 & 4 & $>18.8$ & 1.02 & 250 \\
\hline 21 & 0.5 & 1 & 4 & 1.67 & 0.46 & 277 \\
\hline 22 & 0.5 & 0.5 & 4 & 4.12 & 0.69 & 450 \\
\hline 23 & 1 & 2 & 2 & 3.35 & 0.31 & 67.5 \\
\hline
\end{tabular}

-: Data not available.

not shown).

The peptide chain could be elongated by the coupling of an acylated amino acid such as $N$-acylphenylalanine to the $N$-terminus of the nucleus. In the phenylalanyl series, the chain length of the $\mathrm{N}$-acyl group was varied from $\mathrm{C}-8$ to $\mathrm{C}-14$. We observed that the good in vitro activity at the $\mathrm{C}-10$ and higher chain lengths translated adequately in vivo. Acyl groups with chain lengths from C-9 to C-11 were associated with analogs of lower toxicity. An additional amino acid did not bestow any therapeutic advantage; this was also the case with the alkyl-amino acids. The data in Table 4 includes the antimicrobial properties of a number of amino aroyl and aralkyl analogs. The longer chain lengths in the amide function were associated with good in vitro and in vivo activity and demonstrated the wide variety of structural changes that could be introduced without major changes in the activity spectrum. The dodecanoylaminophenacetyl derivative had the best activity and the lowest toxicity of this group. In summary, most of these analogs retained much of the characteristics of the parent A21978C antibiotic with no significant change in the in vitro and in vivo antimicrobial spectra.

Our criteria for evaluation required that these derivatives have antimicrobial activity and $\mathrm{LD}_{50}$ values that were at least comparable to the parent $\mathrm{A} 21978 \mathrm{C}_{1}$ in order to be considered for further study. The analogs meeting these criteria included the decanoyl (LY146032) (4), and the undecanoyl (5) fatty acid acyl analogs, whose properties closely resembled those of the parent antibiotic. Two other analogs: The $N$-decanoylphenylalanyl (13) and the $N$-dodecanoyl-p-aminophenacetyl (22) com- 
Table 5. Comparative toxicity of A21978C analogs.

\begin{tabular}{lcc}
\hline \multicolumn{1}{c}{ A21978C analog } & $\begin{array}{c}\text { Mouse acute } \\
(1 \mathrm{~g} / \mathrm{kg}, \mathrm{iv})\end{array}$ & $\begin{array}{c}\text { Rat subchronic } \\
(150 \text { or } 300 \mathrm{mg} / \mathrm{kg} / \text { day } \\
\text { for } 7 \text { days, sc) }\end{array}$ \\
\hline A21978C & $7 / 10^{\mathrm{a}}$ & $\downarrow \mathrm{BWG}-150,300^{\mathrm{b}}$ \\
& & $\uparrow \mathrm{SGPT}-300$ \\
$n$-Decanoyl (LY146032) & $2 / 10$ & $\uparrow \mathrm{SGPT}-300$ \\
$\alpha$ - $N$-(n-Decanoyl)-L-phenylalanyl- & $10 / 10$ & $\downarrow$ BWG-300 \\
& & $\uparrow \mathrm{SGPT}-150,300$ \\
& & $\uparrow \mathrm{BUN-300}$ \\
$N$-(n-Dodecanoyl)-p-aminophenacetyl- & $9 / 10$ & Nephrotoxicity \\
$n$-Undecanoyl- & $10 / 10$ & $\downarrow$ BWG-150,300 \\
& & $\downarrow$ BWG-150,300 \\
& & $\uparrow$ SGPT-150 \\
& & Nephrotoxicity \\
& & Mortality \\
\hline
\end{tabular}

a Number dead/number dosed.

b Arrows indicate increase $(\uparrow)$ or decrease $(\downarrow)$ from control values.

BWG: Body weight gain, SGPT: serum glutamyl-pyruvate transferase, BUN: blood urea nitrogen.

pounds were also chosen. These compounds were compared in a study designed to reveal any important differences in their toxicity profiles. The mouse survival test studies summarized in Table 5 showed that the decanoyl analog of A21978C gave the best survival while A21978C and the other analogs caused significantly more mortality. Moreover, the decanoyl analog (4) had only modest toxicity in the rat subchronic study with serum glutamyl-pyruvate transferase (SGPT) elevations at only the higher dose level. There was no sign of specific organ involvement. Therefore, the decanoylA21978C analog, LY146032, also known as daptomycin, was recognized as a potentially useful analog and is currently undergoing clinical studies.

\section{Experimental}

The following instruments were used in this study: ${ }^{1} \mathrm{H}$ NMR spectrometer Bruker WH360; UV spectrometer, Cary 15; ORD and CD spectropolarimeter, Perkin-Elmer 241 and Jasco J40AS; IR spectrophotometer, Beckman IR426; IR spectrometer, Beckman IR426; high resolution mass spectrometer, Varian MAT731; amino acid analysis, Beckman 120B amino acid analyzer equipped with a Bio-Cal autosample applicator and programmer and single Durrum BC-1A resin; preparative HPLC work was done on a Waters PREP-500 chromatograph. Amino acids and acid chlorides were obtained from commercial sources.

\section{Preparation of A21978C Nucleus}

The fermentation of A21978C was carried out according to methods outlined elsewhere and resulted in the isolation of $\mathrm{A} 21978 \mathrm{C}$ complex. ${ }^{1)}$ A fermentation of A. utahensis was carried out according to the procedure described in U.S. Patent No. 4,396,543. After a 66-hour growth period, $100 \mathrm{~g}$ of crude $\mathrm{A} 21978 \mathrm{C}$ complex was added to the A. utahensis culture, and the disappearance of the antimicrobial activity was monitored by assay against Micrococcus luteus.

Whole fermentation broth (20 liters) was filtered with a filter aid (Hyflo Super-Cel) and the mycelial cake discarded. The filtrate was passed through a column containing 1.5 liters of Diaion high porous polymer HP-20 resin. The effluent was discarded and the column was washed with water to remove residual filtered broth and this effluent also discarded. The column was eluted with water $-\mathrm{CH}_{3} \mathrm{CN}$ mixtures (10 liters each of $95: 5,9: 1$ and $4: 1$ ) collecting 1-liter fractions. This elution was monitored by analytical HPLC using Silica gel/C18 and a solvent system of water - MeOH $(3: 1)$ containing $0.2 \%$ ammonium acetate and the detector set at $254 \mathrm{~nm}$. Fractions containing the nucleus were com- 
bined, concentrated under reduced pressure to remove $\mathrm{CH}_{3} \mathrm{CN}$ and freeze-dried to give purified A21978C nucleus (40.6 g) as a white, amorphous solid which fluoresces under short wavelength UV light: Fast atom bombardment mass spectrum (FAB-MS) $m / z 1,466(\mathrm{M}+1)$, calcd for $\mathrm{C}_{82} \mathrm{H}_{84} \mathrm{~N}_{17} \mathrm{O}_{25}$ : 1,466.58249, found: 1,466.5808; IR (KBr) cm $\mathrm{cm}^{-1} 1655$ (s), 1530 (s); UV $\lambda_{\text {max }}^{\text {Etor }} \mathrm{nm}(\varepsilon) 223(41,482), 260$ $(8,687), 366(4,000) ; p K a(66 \%$ DMF $) 5.2,6.7,8.5,11.1$.

\section{Preparation of the $N$-Orn-tert-BOC-A21978C Complex}

A21978C complex, obtained by fermentation by the procedure outlined in U.S. Patent No. $4,208,403,(5 \mathrm{~g})$ was dissolved in water and the $\mathrm{pH}$ adjusted from 4.1 to 9.5 with $1 \mathrm{~N} \mathrm{NaOH}(10 \mathrm{ml})$. Di-tert-butyldicarbonate $(1 \mathrm{ml})$ was added with stirring at room temperature for 2 hours. The $\mathrm{pH}$ was maintained at 9.5 by the manual addition of $5 \mathrm{~N} \mathrm{NaOH}$. The reaction was monitored by TLC (silica gel, $\mathrm{CH}_{3} \mathrm{CN}$ - water $(7: 3$ and $8: 2)$ using UV detection). After a brief induction period the reaction became turbid. The reaction was continued until the rate of turbidity increase and base consumption decreased to a minimum. The reaction was allowed to proceed for an additional 90 minutes and the reaction mixture was lyophilized immediately to give $7.1 \mathrm{~g}$ of crude $N$-Orn-tert-BOCA21978C complex.

\section{Preparation of $N$-Orn-tert-BOC-A21978C Nucleus}

The crude $N$-Orn-tert-BOC-A21978C complex $(1,200 \mathrm{~g})$ was added to a growing 66 -hour $A$. utahensis culture using the fermentation conditions described in the patent cited above. The fermentation was run until assays for antimicrobial activity using $M$. luteus were negative.

Fermentation broth (100 liters) was filtered using filter aid (Hyflo Super-Cel) and the filtrate passed over a column containing 7.5 liters of Diaion HP-20 resin. The column was washed with water (38 liters) followed water $-\mathrm{CH}_{3} \mathrm{CN}$ mixtures, $95: 5$ (40 liters), $9: 1$ (40 liters) and $85: 15$ (100 liters). The elution was monitored by analytical HPLC using Silica gel/C18 column with UV detection $(280 \mathrm{~nm})$. Fractions containing the nucleus were combined, concentrated under vacuum to remove solvent and freeze-dried to give $298 \mathrm{~g}$ of crude $N$-Orn-tert-BOC-A21978C nucleus.

This $\mathrm{N}$-Orn-tert-BOC-A21978C nucleus preparation $(30 \mathrm{~g})$ was dissolved in water $-\mathrm{CH}_{3} \mathrm{CN}(9: 1)$ containing $0.2 \% \mathrm{AcOH}$ and $0.8 \%$ pyridine and chromatographed on a $4.7 \times 192-\mathrm{cm}$ steel column containing Silica gel (Quantum LP-1)/C18 equilibrated in the same solvent. The column was developed under pressure with water $-\mathrm{CH}_{3} \mathrm{CN}-\mathrm{MeOH}(80: 15: 5)$ containing $0.2 \% \mathrm{AcOH}$ and $0.8 \%$ pyridine collecting $350 \mathrm{ml}$ fractions. The progress of the chromatography was monitored by analytical HPLC. Fractions containing the product were concentrated under vacuum and freeze-dried to give purified $\mathrm{N}$-Orn-tert-BOC nucleus $(18.4 \mathrm{~g}, 90 \%$ purity) as an amorphous solid which fluoresced under short wave length UV light: FAB-MS $m / z$ 1,566 (M+1), calcd for $\mathrm{C}_{67} \mathrm{H}_{22} \mathrm{~N}_{17} \mathrm{O}_{27}: 1,566.634860$, found: 1,566.6342; IR (KBr) cm ${ }^{-1} 1710$ (sh), 1660, 1530; UV $\lambda_{\max }^{90 \% \text { EtoH }} \mathrm{nm}(\varepsilon) 220(42,000), 260(10,600), 366$ $(\sim 4,000)$; HPLC retention time: 6 minutes on $4.6 \times 300 \mathrm{~mm}$ column of Silica gel/C18 using a water $\mathrm{CH}_{3} \mathrm{CN}-\mathrm{MeOH}(80: 15: 5)$ solvent containing $0.2 \%$ ammonium acetate at a flow rate of $2 \mathrm{ml} / \mathrm{minute}$ with UV detection at $280 \mathrm{~nm}$.

\section{General Procedure for the Preparation of $N$-Alkanoyl-amino Acids}

The appropriate alkanoyl acid chloride was added dropwise to a solution of the amino acid $(1: 1$ mol ratio) in pyridine to bring the final concentration of reactants to 0.1 to $0.2 \mathrm{M}$. The reaction mixture was stirred for 3 to 6 hours at ambient temperature and poured into water to give a precipitate. The product was collected by filtration and crystallized from $\mathrm{MeOH}$.

\section{General Procedure for Preparation of 2,4,5-Trichlorophenyl Active Esters}

(A): The following preparation of 2,4,5-trichlorophenyl $n$-decanoate illustrates use of acid chlorides for the synthesis of active esters: A solution of decanoyl chloride $(5.6 \mathrm{ml})$ and 2,4,5-TCP $(5.6 \mathrm{~g})$ in ether $(1$ liter $)$ and pyridine $(120 \mathrm{ml})$ was stirred for 4 hours. The reaction mixture was filtered and the solvents removed under reduced pressure. The crude active ester was purified on a silica gel column (Woehlm) using toluene as the eluent. Fractions were monitored by TLC and appropriate fractions were pooled to yield the desired 2,4,5-trichlorophenyl $n$-decanoate $(10.4 \mathrm{~g})$.

(B) The $N, N^{\prime}$-Dicyclohexylcarbodiimide Method for Active Ester Preparation: The following 
procedure illustrates the synthesis of active esters using $N, N^{\prime}$-dicyclohexylcarbodiimide as the coupling agent:

A solution of $N$-(n-decanoyl)-L-phenylalanine $(31.9 \mathrm{~g}, 0.1 \mathrm{~mol})$ and $2,4,5-\mathrm{TCP}(19.7 \mathrm{~g}, 0.1 \mathrm{~mol})$ in 1 liter of anhydrous ether was treated with $N, N^{\prime}$-dicyclohexylcarbodiimide $(20.6 \mathrm{~g}, 0.1 \mathrm{~mol})$. The reaction was stirred overnight at room temperature and the precipitate of $N, N^{\prime}$-dicyclohexylurea (DCU) was removed by filtration. The filtrate was concentrated to dryness under reduced pressure. Trituration of the residue with ether, removal of the solids DCU by filtration and evaporation of the solvent under reduced pressure gave a solid. This solid was crystallized from $\mathrm{CH}_{3} \mathrm{CN}$ to give $\mathrm{N}$-(n-decanoyl)L-phenylalanyl $2,4,5$-trichlorophenylate, $\mathrm{mp} 122 \sim 124^{\circ} \mathrm{C}$.

\section{Preparation of $N$-Trp-[N-(n-decanoyl)-L-phenylalanyl]- $N$-Orn-tert-BOC-A21978C Nucleus}

The following procedure serves to illustrate the general method used here for the acylation of the $N$-Orn-tert-BOC-A21978C nucleus at the $N$-terminal amino group of the latter peptide.

A solution of $N$-(n-decanoyl)-L-phenylalanyl-2,4,5-trichlorophenylate $(1.0 \mathrm{~g}, 0.02 \mathrm{~mol})$ and $N$ Orn-tert-BOC-A21978C nucleus $(10 \mathrm{~g}, 0.006 \mathrm{~mol})$ in anhydrous dimethylformamide (1 liter) was stirred at room temperature for 96 hours under an inert atmosphere of nitrogen. The solvent was removed under reduced pressure and the residue stirred ( 2 hours) with 1 liter of diethyl ether $-\mathrm{CHCl}_{3}$ (4:1) mixture to remove the halophenol biproducts. The solid residue was collected by filtration $(10.3 \mathrm{~g})$ and purified using preparative HPLC (Waters PREP LC/System 500 unit equipped with PrePak-500/C18 column as the stationary phase). Isocratic elution was carried out with a water - MeOH $\mathrm{CH}_{3} \mathrm{CN}$ solvent system $(2: 1: 2)$ collecting $250-\mathrm{ml}$ samples every 60 seconds. The desired material eluted after 2 liters of eluent had been used and was identified by reversed phase TLC (Silica gel/C18, water - $\mathrm{MeOH}-\mathrm{CH}_{3} \mathrm{CN}(3: 3: 4)$, detected by Van Urk's spray reagent (yellow)). Combined fractions were reanalyzed by the TLC system described above and by bioautography (silica gel TLC, $\mathrm{CH}_{3} \mathrm{CN}$ $\mathrm{Me}_{2} \mathrm{CO}$ - water $(2: 2: 1)$ vs. $M$. luteus as the detecting organism). The procedure gave $6.02 \mathrm{~g}$ of $\mathrm{N}$ $\operatorname{Trp}-[N$-(n-decanoyl)-L-phenylalanyl]- $N$-Orn-tert-BOC-A21978C nucleus.

\section{Preparation of $N$-Trp-[N-(n-decanoyl)-L-phenylalanyl]A21978C Nucleus}

The following procedure outlines the procedure used to deblock the $N$-Orn-tert-BOC-A21978C analog. A flask (100-ml) (was cooled in an ice bath to $\left.5^{\circ} \mathrm{C}\right)$, containing $N$-Trp- $[N-(n$-decanoyl)-Lphenylalanyl]- $N$-Orn-tert-BOC-A21978C nucleus $(6.03 \mathrm{~g}, 0.008 \mathrm{~mol})$ and anhydrous FTA containing $2 \%$ anisole $(50 \mathrm{ml})$ was added in one portion. After the mixture went into solution ( 2 minutes) the reaction was stirred for 10 minutes under nitrogen and evaporated under reduced pressure at temperatures below $40^{\circ} \mathrm{C}$. The semi-solid residue was triturated twice with ether - methylene chloride $(4: 1)$, two $100-\mathrm{ml}$ portions, and the residual solid was isolated by filtration. This solid was washed with ether to give the TFA salt. This salt was dissolved in water $(50 \mathrm{ml})$ and the solution was adjusted to pH 5.4 with pyridine to give $6.1 \mathrm{~g}$ of a white solid after lyophilization to remove the pyridinium trifluoroacetate. The white solid was dissolved in $35 \mathrm{ml}$ of MeOH and purified by preparative HPLC using a Waters PREP 500 equipped with a reversed phase C18 Silica gel column and eluting with a step gradient of water $-\mathrm{MeOH}-\mathrm{CH}_{3} \mathrm{CN}$ containing $0.1 \%$ pyridinium acetate in ratios of $3: 1: 2,2: 1: 2$ and $1: 2: 2$, and collecting $250-\mathrm{ml}$ fractions every 60 seconds. The progress of the chromatography was followed by reversed phase TLC as with the chromatography of the protected analog (see above). The desired $N$-Trp-[N-(n-decanoyl)-L-phenylalanyl]A21978C nucleus was eluted with the $2: 1: 2$ solvent and the combined fractions gave $2.23 \mathrm{~g}$ of a cream colored product after lyophilization.

\section{Procedures for Direct Acylation of A21978C Nucleus}

Method A-Modified Schotten-Baumann Reaction: The acylation of the A21978C nucleus with alkanoyl or alkenoyl chlorides was carried out according to this general procedure. The A21978C nucleus $(2.0 \mathrm{~g}, 1.35 \mathrm{mmol})$ was dissolved in $200 \mathrm{ml}$ of pyridine - water $(9: 1)$. The acylating agent $\left(18 \sim 20 \mathrm{mmol}\right.$ excess acid chloride dissolved in $15 \mathrm{ml} \mathrm{Me}{ }_{2} \mathrm{CO}$ ) is added dropwise over $1 \sim 3$ hours and the reaction allowed to stir for an additional 3-hour at ambient temperatures. The acetone was removed under reduced pressure. The aqueous phase which remained was diluted with $200 \mathrm{ml}$ of water and the $\mathrm{pH}$ of the solution was adjusted to $\mathrm{pH} 3$ to 3.4 with glacial acetic acid. The solution 
was washed eight times with ethyl ether and the aqueous layer was lyophilized.

The crude acylated nucleus was purified by preparative HPLC. The product was dissolved in $4 \sim 6 \mathrm{ml}$ of water or the eluting solvent and injected onto a stainless steel column $(84 \times 1.6 \mathrm{~cm})$ packed with a LP-1/C18 support. The column was eluted with a solvent system of the following composition; water - $\mathrm{MeOH}-\mathrm{CH}_{3} \mathrm{CN}$ - pyridine - $\mathrm{AcOH}(45: 15: 40: 2: 2)$ at $105 \sim 140 \mathrm{~kg} / \mathrm{cm}^{2}$ pressure and at a flow rate of $10 \sim 12 \mathrm{ml} /$ minute using a Milton-Roy LDC duplex pump and a detector set at $280 \mathrm{~nm}$. The fractions were combined on the basis of TLC using reversed phase plates (Whatman KC18) and the same solvent used in the HPLC separation. The product was detected on these plates with UV light. Purity of the combined desired fractions were determined by analytical HPLC (C18 Microbondapak, Waters Co.), with the solvent system used in the preparative separation using a UV monitor set at $280 \mathrm{~nm}$. The appropriate fractions were concentrated under reduced pressure and lyophilized. Purity ranged from $85 \sim 90 \%$ and was assessed by HPLC, TLC and UV spectra.

Method B-2,4,5-Trichlorophenyl Active Ester Method: A solution of lauric acid (200 mg, $1 \mathrm{mmol}$ ) and 2,4,5-TCP $(220 \mathrm{mg}, 1.1 \mathrm{mmol})$ in ether $(20 \mathrm{ml})$ was stirred for 1 hour and $206 \mathrm{mg}$ of $N, N^{\prime}$-dicyclohexylcarbodiimide was added in one portion. The reaction mixture was stirred for 24 hours at ambient temperatures under an inert atmosphere and filtered to remove the precipitated DCU. The precipitate was washed with ether and the filtrate was evaporated to dryness under reduced pressure. The residue was triturated three times with ether and filtered to remove residual DCU. The filtrate was concentrated to dryness to give a gum $(482 \mathrm{mg})$ which crystallized from petroleum ether-B - ether $(10: 1)$ to give $220 \mathrm{mg}(51 \%)$ of lauroyl $2,4,5$-trichlorophenylate as white needles, $\mathrm{mp}$ $59 \sim 60^{\circ} \mathrm{C}$.

A solution of $\mathrm{A} 21978 \mathrm{C}$ nucleus $(50 \mathrm{mg}, 0.031 \mathrm{mmol}$ ), lauroyl 2,4,5-trichlorophenolate $(12 \mathrm{mg}$, $0.032 \mathrm{mmol}$ ) in $6 \mathrm{ml}$ of DMF was stirred for 3 hours at room temperature and overnight at $50^{\circ} \mathrm{C}$ under nitrogen. The reaction mixture was concentrated under vacuum to $1 / 4$ volume controlling the temperature below $55^{\circ} \mathrm{C}$ and diluting with excess water and $\mathrm{CHCl}_{3}$. The aqueous layer was washed twice with $\mathrm{CHCl}_{3}$ and concentrated under vacuum without the use of heat to remove volatiles to give a yellow powder which showed that $30 \%$ of A21978C nucleus was still present. The reaction was examined by TLC (reversed phase Whatman $\mathrm{KC} 18$ Silica gel plates, $75 \% \mathrm{MeOH}-\mathrm{H}_{2} \mathrm{O}, 0.1 \%$ pyridinium acetate, Von Urk's or Ehrlich's spray) and showed a series of three spots in the lower third of the plate. The central major spot had the identical $\mathrm{Rf}$ as the analog prepared by the SCHOTTENBAUMAN method. The other spots were not identified.

Methods for Evaluation of Antibiotic and Toxicity Parameters

In vitro antimicrobial assays were done by the standard agar dilution method using MuellerHinton agar supplemented with $1 \%$ supplement C (Difco Laboratories, Detroit, Michigan). Mouse protection tests $\left(\mathrm{ED}_{50}\right)$ were run using 5 groups of 8 mice per group $(19 \sim 21 \mathrm{~g}$ and random sex). The mice were inoculated with the infecting organism by the intraperitoneal route. The mice were treated with the appropriate dilution of the antibiotic at 1 and 5 hours post-infection by the subcutaneous route and observed for 7 days. All of the infected control animals died during this period. The $\mathrm{ED}_{50}$ was calculated by the REED-MuENCH method. ${ }^{11)}$ Acute toxicity, as expressed by the $\mathrm{LD}_{50}$ value, was determined using mice $(19 \sim 21 \mathrm{~g}$, random sex and four per group). These animals were administered the antibiotic by the intraperitoneal route and observed for 7 days. $\mathbf{L D}_{50}$ values were calculated by the REED-MUENCH method. ${ }^{11}$

\section{Acknowledgments}

The authors wish to acknowledge the expert technical assistance of Mr. D. R. BERRY, D. R. Horton, Gladys M. Clem, Lyell Huckstep and members of the Fermentation Products Isolation Pilot Plant. We also thank Mrs. Verna Newton and Mrs. Louise Crandall for their assistance in preparation of this manuscript.

\section{References}

1) Debono, M.; M. Barnhart, C. B. Carrell, J. A. Hoffmann, J. L. Occolowitz, B. J. Abbott, D. S. 
Fukuda, R. L. Hamill, K. Biemann \& W. C. Herlihy: A21978C, a complex of new acidic peptide antibiotics: Isolation, chemistry, and mass spectral structure elucidation. J. Antibiotics 40: 761 777, 1987

2) Hollstein, U.: Nonlactam antibiotics. In Burger's Medicinal Chemistry. Part II. Ed., M. WolfF, pp. 173 288, John Wiley \& Sons, New York, 1979

3) Debono, M.; B. J. Abbott, V. M. Krupinski, R. M. Molloy, D. R. Berry, F. T. Counter, L. C. Howard, J. L. OTT \& R. L. HAMLL: The synthesis and structure-activity relationships of new analogs of the gram positive lipopeptide antibiotic A21978C. Program and Abstracts of the 24th Intersci. Conf. on Antimicrob. Agents Chemother., No. 1077, p. 280, Washington, D. C., Oct. $8 \sim 10,1984$

4) Counter, F. T.; P. W. Ensminger \& L. C. Howard: A21978C, a complex of new acidic peptide antibiotic: Biological activity and toxicity. Program and Abstracts of the 20th Intersci. Conf. on Antimicrob. Agents Chemother., No. 69, New Orleans, Sept. 22 24, 1980

5) Eltopoulos, G. M.; C. Thauvin, B. Gerson \& R. C. Moellering, Jr.: In vitro activity and mechanism

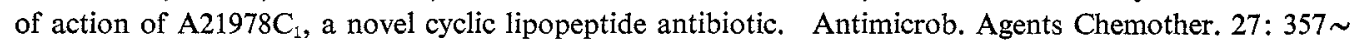
362,1985

6) Fukuda, D. S.; B. J. Abbott, D. R. Berry, L. D. Boeck, M. Debono, R. L. Hamill, V. M. Krupinski \& R. M. Mollox: Deacylation and reacylation of A21978C, a acidic lipopeptide antibiotic: Preparation of new active analogs. Program and Abstracts of the 24th Intersci. Conf. on Antimicrob. Agents Chemother., No. 1076, p. 280, Washington, D.C., Oct., $8 \sim 10,1984$

7) Engelhardt, J. A.; A. M. Surprenant \& R. S. Pekarek: A21978C, a complex of new acidic peptide antibiotics: Therapy of experimental Streptococcus faecalis endocarditis with $\mathrm{A}_{21978 \mathrm{C}_{1} \text {. Program and }}$ Abstracts of the 20th Intersci. Conf. on Antimicrob. Agents Chemother., No. 70, New Orleans, Sept. 22 24,1980

8) KrmuRA, Y. \& S. HirAKI: Behavior of polymixin acylase for ion-exchange cellulose column chromatography produced by Pseudomonas sp. M-6-3 strain. Bulletin of Mukagawa Women's University (Japanese) $14: 243 \sim 252,1966$

9) ShoJ, J. \& T. Kato: The amino acid sequence of cerexin A. (Studies on antibiotics from the genus bacillus. VII). J. Antibiotics 28: 764 769, 1975

10) Kreinschmid, W.; W. E. Wright, F. W. Kavanaugh \& W. M. Stark (Eli Lilly): Penicillin deacylation via Actinoplanaceae fermentation. U.S. 3,150,059, Sept. 22, 1964

11) ReEd, L. J. \& H. Muench: A single method for estimating 50 percent endpoints. Am. J. Hyg. 27: $493 \sim 497,1938$ 